\title{
Arguing Against the Expressive Function of Punishment: Is the Standard
}

\section{Account that Insufficient?}

\author{
Ambrose Y. K. Lee*
}

\section{Abstract}

This paper critically appraises the arguments that have been offered for what can be called 'the expressive function of punishment'. According to this view, what distinguishes punishment from other kinds of non-punitive hard treatment is that punishment conveys a censorial/reprobative message about what the punished has done, and that this expressive function should therefore be accepted as part of the nature and definition of punishment. Against this view, this papers argues that the standard account of punishment, according to which punishment is a kind of hard treatment that is imposed on an alleged offender in response to her alleged wrongdoing, can already properly account for punishment and distinguish it from other kinds of hard treatment when it is properly clarified and understood. Thus there is no need to accept the expressive function of punishment in addition to the standard account when it comes to the nature and definition of punishment.

\section{Introduction}

Ever since it was first advanced by Feinberg, ${ }^{1}$ many theorists and philosophers have now come to accept the "expressive function of punishment". ${ }^{2}$ According to this now rather

\footnotetext{
* Orchid ID: 0000-0002-8955-2711. Email: y.a.lee@surrey.ac.uk.

1 Joel Feinberg, "The Expressive Function of Punishment," The Monist 49 (1965): 397-423

2 E.g. David Boonin, The Problem of Punishment (Cambridge: CUP, 2009), 21-23; Antony Duff, Punishment, Communication, and Community (Oxford, New York: OUP, 2001), xiv-xv or more recently, "How not to Define Punishment," Philosophy and Public Issues 5 (1) (2015): 25-41, 38-41; Bill Wringe, An Expressive Theory of Punishment (New York: Palgrave Macmillan, 2016), 103.
} 
This is a post-peer-review, pre-copyedit version of an article published in Law and Philosophy. The final authenticated version is available online at: http://dx.doi.org/10.1007/s10982-019-09353-7.

widely held view about the nature and definition of punishment, what distinguishes punishment from other kinds of non-punitive hard treatment is that punishment conveys a censorial/reprobative message about what the punished has done. More importantly is the way in which this censorial/reprobative message is conveyed in punishment. Punishment does not simply convey this message in a way that is separate from and independent of the hard treatment - for example by the conviction that happens prior to the hard treatment. Rather, it is conveyed more specifically by the hard treatment in question. As Feinberg explains, "It would be more accurate in many cases to say that the unpleasant treatment itself expresses the condemnation, and that this expressive aspect of his incarceration is precisely the element by reason of which it is properly characterized as punishment and not mere penalty"; or more simply (and dramatically), "the very walls of his cell condemn him..."3

The aim of this paper is to ask whether there are good reasons for accepting this expressive function as part of the nature and definition of punishment. Following the title of Feinberg's paper, I shall simply refer to this view as 'the expressive function of punishment'. Central to the arguments that have so far been offered for this view is that this expressive function is needed to properly account for punishment and distinguish it from other kinds of non-punitive hard treatment. ${ }^{4}$ However, I shall argue that we can also properly account for punishment and distinguish it from other kinds of hard treatment by attending more closely to the other defining features of punishment that are already captured in what I shall refer to as the 'standard account', according to which punishment is a kind of hard treatment that is

\footnotetext{
${ }^{3}$ Feinberg (n 1) 402.

${ }^{4}$ See txt at nn. $10 \& 11$.
} 
This is a post-peer-review, pre-copyedit version of an article published in Law and Philosophy. The final authenticated version is available online at: http://dx.doi.org/10.1007/s10982-019-09353-7.

imposed on an alleged offender in response to her alleged wrongdoing. ${ }^{5}$ If that is true, then no good reasons have yet been given for the expressive function of punishment.

It is also important to stress at the outset that I am not trying to deny that punishment can sometimes have an expressive function. As I shall explain later on, the hard treatments in punishment (or particular instances of them) can sometimes be used or so happen to be seen as conveying a censorial/reprobative message. What I am keen to deny is simply that this expressive function is a necessary, essential or defining feature of punishment. This is what I mean when I object to the expressive function of punishment.

Nothing that I shall argue in this paper implies that communicative/expressive justificatory theories of punishment are mistaken and that punishment cannot be justified in virtue of it communicating or expressing certain kinds of censorial/reprobative messages about the wrongdoings that wrongdoers have committed. ${ }^{6}$ This paper is concerned with the expressive function in relation to what punishment is and not in relation to its justification

Why does this matter? It matters because it is important in its own right to not confuse what is contingent with what is necessary, essential or definitive of punishment. Furthermore, the expressive function of punishment does have other important normative implications concerning the justification of punishment. Thus for example, as shown by Feinberg, Von Hirsch and Ashworth, ${ }^{7}$ if the expressive function of punishment is true, then this gives us a plausible argument for requiring proportionality in punishment that is independent from any

\footnotetext{
${ }^{5}$ H. L. A. Hart, Punishment and Responsibility $2^{\text {nd }}$ edn. (Oxford, New York: OUP, 2008), 4-5. By 'wrongs', I refer not only to 'moral wrongs' but also 'legal wrongs'.

${ }^{6}$ For different versions of communicative/expressive justificatory theories, see e.g. Duff, Punishment, Communication, and Community (n 2), Wringe (n 2) and Christopher Bennett, The Apology Ritual (Cambridge: CUP, 2008).

7 Joel Feinberg, The Moral Limits of the Criminal Law Vol. 4: Harmless Wrongdoing (New York, Oxford: OUP, 1988), 149-155; and Andrew Von Hirsch \& Andrew Ashworth, Proportionate Sentencing (Oxford, New York: OUP, 2005), 134-137.
} 
This is a post-peer-review, pre-copyedit version of an article published in Law and Philosophy. The final authenticated version is available online at: http://dx.doi.org/10.1007/s10982-019-09353-7.

justificatory theories of punishment. ${ }^{8}$ However, if the expressive function of punishment is not true, then this argument will not necessarily hold for all punishments simply in virtue of them being punishments. Rather, it will contingently depend on whether the hard treatments in question are so happen to be used or seen as conveying a censorial/reprobative message. I shall leave it for another occasion to spell out in detail the implications if we reject the expressive function of punishment. What this paper aims to do is simply to make a modest contribution in favour of the antecedent.

\section{Arguments for the Expressive Function of Punishment}

As explained earlier, central to the arguments that have so far been offered for the expressive function of punishment is that this function is needed to properly account for punishment and distinguish it from other kinds of non-punitive hard treatment. In particular, they start with what I shall be referring to as the 'standard account' of the nature and definition of punishment, according to which punishment is a kind of hard treatment that is imposed on an alleged offender in response to her alleged wrongdoing. They then go on to argue how this standard account fails to properly account for punishment and distinguish it from other kinds of non-punitive hard treatment unless it also includes the expressive function of punishment. ${ }^{9}$

\footnotetext{
${ }^{8}$ By 'proportionality in punishment', I am referring to the admittedly imprecise requirement that the relative severity of the hard treatment in punishments should correspond to the relative seriousness of the wrongs in question, and that they should neither be so severe nor so lenient such that they fail to accurately reflect the seriousness of the wrongs to which they are punishments for. For further discussion of this, see e.g. ibid 138148.

${ }^{9}$ There is another way in which the standard account, as I have portrayed here, is incomplete. It fails to distinguish between punishment from vigilantism and revenge, and that an 'imposed by authority' criterion should be added to the standard account (see e.g. Hart (n 5) 5). I shall put this alleged incompleteness to one side for the purposes of this paper. For further discussion of this criterion, see e.g. Boonin (n 2) 23-24 and Wringe (n 2) 32-33 \& 101-102.
} 
This is a post-peer-review, pre-copyedit version of an article published in Law and Philosophy. The final authenticated version is available online at: http://dx.doi.org/10.1007/s10982-019-09353-7.

Thus in one of the most famous arguments for the expressive function of punishment, Feinberg argues that the standard account fails to distinguish punishment from what he refers to as mere "penalties", which includes "parking tickets, offside penalties, sackings, flunkings, and disqualifications". ${ }^{10}$ More recently, Boonin has also argued how the standard account fails to exclude from punishment the case in which a prospective gang member is subjected to hard treatment in response to committing wrongs as part of an initiation ceremony. ${ }^{11}$

Feinberg and Boonin are too quick in accepting the alleged inadequacy of the standard account here. As I shall show in the rest of this paper, the standard account can indeed distinguish punishment from these other kinds of non-punitive hard treatment when it is properly clarified and understood. In particular, in response to Boonin, I shall argue that his argument trades on an ambiguity about what it means to respond to an alleged wrongdoing. In response to Feinberg, I shall argue how it is not obvious (to me at least) that all instances of what he refers to as 'mere penalties' are not and should not be considered as punishments. What then distinguishes those that are punishments and those that are not, I shall argue, is precisely the standard account when it is suitably understood and clarified.

My argument against the expressive function of punishment therefore depends on having a good case for the standard account as I understand it. This is precisely what I shall provide in the rest of this paper. My discussion will be divided into three main parts. I shall begin by clarifying how the element of 'hard treatment' should be understood in the standard account. This forms the basis for my subsequent discussions. I shall then move on to what it means to respond to an alleged wrongdoing and Boonin's alleged counterexample for the

\footnotetext{
${ }^{10}$ Feinberg (n 1) 398.

${ }^{11}$ Boonin (n 2) 22-23.
} 
This is a post-peer-review, pre-copyedit version of an article published in Law and Philosophy. The final authenticated version is available online at: http://dx.doi.org/10.1007/s10982-019-09353-7.

standard account, before finally coming back to Feinberg's mere penalties and other related examples.

\section{Hard Treatment in the Standard Account}

While it is widely accepted that hard treatment must be included in any adequate account of the nature and definition of punishment, there is some debate over what exactly it consists of. According to Hart, it "must involve pain or other consequences normally considered unpleasant". ${ }^{12}$ I follow many others in contending that the hard treatment in punishment does not simply involve the mere harming of others. Rather, it involves intentionally harming others. ${ }^{13}$ In other words, the harms that constitute hard treatment in punishment are therefore intended harms, and not merely accidental or foreseeable harms. Following Boonin, I shall refer to this as the "Intending harm requirement". ${ }^{14}$

One argument that is frequently cited for this requirement is precisely the fact that 'intended harms' helps to distinguish punishment from many other kinds of non-punitive hard treatment that also involve the harming of others. Take (non-punitive) compensations for example; it is at least foreseeable that those who are required to compensate will often be harmed by them. However, what is intended in such compensations is not the infliction of harm on those who also harm others, but to bring those who have been harmed by others back to the level where they were at before. This seems to be precisely that which

\footnotetext{
12 Hart (n 5) 4.

${ }^{13}$ E.g. Boonin (n 2) 12-17; and Nathan Hanna, "Say What? A Critique of Expressive Retributivism," Law and Philosophy 27 (2008): 123-150, 124-128.

${ }^{14}$ Boonin (n 2) 15, but see $\mathrm{n}$ 58. I shall talk about how this requirement should be applied to institutional cases of punishment at the end of section 4 . See txt at $n 54$ through to $n 59$.
} 
This is a post-peer-review, pre-copyedit version of an article published in Law and Philosophy. The final authenticated version is available online at: http://dx.doi.org/10.1007/s10982-019-09353-7.

distinguishes such (non-punitive) compensations from punishments. ${ }^{15}$ Similarly, there is also a difference, for example, between being charged a fee for, say getting married, and being charged a fine for, say committing polygamy. If 'harm' is simply understood as something that makes someone worse off in some way or another, ${ }^{16}$ then both fees and fines would count as harming the person who are subjected to them. What then seems to distinguish them from each other is the fact that while the harms of fees are simply foreseeable side-effects of requiring people to bear the administrative costs of (in the above example) getting married, the harms of fines are intended on those who are fined. The same can also be said between on the one hand cases where someone is imprisoned for committing a murder, and on the other hand cases where someone is locked up in a psychiatric hospital after having been found to be criminally insane or is quarantined after having been diagnosed of a highly contagious and deadly disease. ${ }^{17}$

The case for the intending harm requirement does not simply rest on the need and its ability to distinguish between (non-punitive) compensations and punishments, fines from fees, and imprisonments from other kinds of confinements that are not properly nor paradigmatically considered to be punitive. Had the harms that constitute hard treatment in punishment been merely accidental or foreseeable, then we would (and indeed should) consider someone as having been punished even when, due to a (fortunate) twist of fate, she is not harmed by the punishment in question. This, however, seems false. If an offender is, for example, sentenced to be punished by hanging, we would not consider her as having been punished accordingly had the rope broke and she walked away from the 'hanging' unscathed.

\footnotetext{
${ }^{15}$ Sometimes compensations can be punitive - think, for example, exemplary/punitive damages in torts. I think such punitive compensations should rightly be counted as punishments.

${ }^{16}$ Ibid 7. See also txt at n 18.

${ }^{17}$ Ibid 12 and Hanna (n 13) 126.
} 
This is a post-peer-review, pre-copyedit version of an article published in Law and Philosophy. The final authenticated version is available online at: http://dx.doi.org/10.1007/s10982-019-09353-7.

Rather, we would (and I think rightly) at most consider it merely as an attempt to punish her accordingly, but which turned out to be unsuccessful due to the offender's luck. The most straightforward explanation for this is that the harm, i.e. death by hanging, is not merely an accidental or foreseeable part of the punishment in question. Rather, it is an intended part of it; and accordingly, it is an unsuccessful instance of punishment when this intended harm fails to realize in the case that I have just described.

For the purposes of the intending harm requirement, I am using 'harm' very broadly here to refer to anything that makes one's life worse off in one respect or another. ${ }^{18}$ This is intended to not only include what Hart refers to by 'pain or other consequences normally considered unpleasant', but also suffering. It also includes treatments that are considered to be 'burdensome'. ${ }^{19}$

One important thing to emphasize about my broad understanding of harm is that I do not think whether one is harmed or not depends solely on one's subjective state of mind. Thus something can - in this sense 'objectively' - harm someone and make her life worse off even when she does not so happen to believe or experience it as such, and therefore do not have any negative attitudes or emotions towards it. ${ }^{20}$ This is not to deny that someone's life can be made worse off and is therefore harmed by having such negative mental states.

\footnotetext{
${ }^{18}$ As Boonin argues (n 2, 7-8), pro tanto harms are already sufficient for punishment, even when they are not harmful all-things-considered.

${ }^{19}$ Antony Duff \& Zachary Hoskins, "Legal Punishment", The Stanford Encyclopedia of Philosophy (Fall 2017 Edition), Edward N. Zalta (ed.), forthcoming URL $=<$ https://plato.stanford.edu/archives/fall2017/entries/legalpunishment/>, sec. 1. Some might object to my characterization here. For an already repentant offender who embraces and perhaps even seeks her own punishment, the punitive burden is not harmful in one respect but on balance beneficial for her. Rather, it is a benefit since it is precisely by undertaking the burden that she pays her reparative debt. In response, I think we should insist that the punitive burden does indeed harm the offender in the sense described above (how else are we to understand 'burden' if not in terms of making one's life harder, i.e. worse off in at least that one respect?). It is just that for the reasons given she does not see it in such a way. This gives us another reason for adopting an objective sense of 'harm' for the intending harm requirement.

${ }^{20}$ An even more extreme position is that one can be harmed and therefore punished even when one is not aware of being harmed at all. I am not committed to this extreme position for the purposes of this paper.
} 
This is a post-peer-review, pre-copyedit version of an article published in Law and Philosophy. The final authenticated version is available online at: http://dx.doi.org/10.1007/s10982-019-09353-7.

Rather, it is to deny that one's life is made worse off and is harmed by something only when one has certain negative mental states towards it or, for that matter, having its supposed harmful effects on one cancelled by simply having certain positive mental states towards it.

An implication of understanding harm in such a way is that people can still be considered as being punished, even when they themselves do not experience the intended harm of the punishment as such or maybe even have a positive attitude towards it. Thus whipping a masochist who enjoys being whipped can still be counted as punishment, as long as she is objectively harmed by the whipping in the sense that I have described; and arguably she is indeed so at least on account of the physical injuries that result from the whipping. ${ }^{21}$ The same can also be said for the homeless person who prefers the security of the prison to the unpredictability of life on the streets. She is still being harmed by the liberty deprivations that result from her imprisonment. ${ }^{22}$ None of this implies, however, that in cases where they are indeed so punished, we should now not impose additional punishments on them. It all depends on the justificatory theory of punishment that is under consideration. It is entirely conceivable that a justificatory theory may recommend imposing additional punishments when, for example, the end(s) that supposedly justify the original punishment is important enough, and that the original punishment has failed disastrously in achieving it because the punished failed to experience it as harmful.

Of course, much more needs to be said about my above understanding of 'harm'. In particular, more needs to be said on just what exactly can objectively harm and make one's life worse off regardless of their beliefs and attitudes towards them and how this judgement of being made worse off is to be made. Doing this, however, will take us way beyond the

\footnotetext{
${ }^{21}$ And on account of the pain that she experiences if one thinks pain is bad for one's life even if one has a positive attitude towards it.

${ }^{22}$ See also Boonin (n 2) 8-9.
} 
This is a post-peer-review, pre-copyedit version of an article published in Law and Philosophy. The final authenticated version is available online at: http://dx.doi.org/10.1007/s10982-019-09353-7.

purposes of this paper. Given the limited space here, I shall therefore leave it for another occasion and only offer the following more general argument for my above understanding of 'harm' when thinking about the nature and definition of punishment.

Ancient stoics, for example Epictetus, held that the only way in which they can be harmed is by becoming less virtuous. ${ }^{23}$ If people can be harmed only if they so happen to experience it as harmful, then someone who so happen to be a firm and sincere stoic cannot be harmed, nor by extension punished, as long as they remain virtuous themselves. This, however, seems highly implausible. More plausible is the claim that they can indeed be harmed and punished even when they remain virtuous themselves. Of course, more likely than not their punishment in such cases would be unjustifiable, since they remained virtuous; but the plausible thought here is that they are at least unjustifiably punished and harmed had they been punished, and not merely that an unsuccessful attempt was made to (unjustifiably) punish them. Indeed, even in cases where they are justifiably punished (because they committed vices), it seems plausible to think that they have suffered a harm which is in addition to and distinct from whatever harms that they may so happen to suffer in virtue of them being less virtuous. If all this about harming and punishing committed stoics is true, then they suggest adopting something like my above understanding of 'harm' and how someone can indeed be objectively harmed regardless of their subjective mental states.

Although the intending harm requirement is widely accepted, ${ }^{24}$ it is not without its dissenters. Thus according to Zaibert, the hard treatment in punishment can simply be something that $A$ knows would make $B$ suffer without necessarily having the intention that $B$

\footnotetext{
${ }^{23}$ Wringe (n 2) $27 \mathrm{fn} .24$.

${ }^{24}$ See e.g. Boonin (n 2) 13 fn. 14 and Nathan Hanna, "Liberalism and the General Justifiability of Punishment," Philosophical Studies 145 (3) (2009): 325-349, 330.
} 
This is a post-peer-review, pre-copyedit version of an article published in Law and Philosophy. The final authenticated version is available online at: http://dx.doi.org/10.1007/s10982-019-09353-7.

suffers. ${ }^{25}$ More recently, Wringe also argues that it is simply a "treatment that would normally be found burdensome by a typical individual of the kind on whom it is being imposed". ${ }^{26}$

One difficulty with this debate is that people from both sides do not always use the same terms when talking about what I refer to as the intending harm requirement. As a result, it is sometimes not clear whether they are talking about the same thing. In particular, while those who endorse the requirement - for example Boonin and Hanna - speak primarily in terms of 'harm' more generally, ${ }^{27}$ Zaibert and Wringe speak primarily in terms of 'suffering' when talking about the intention that is allegedly required for punishment. ${ }^{28}$

For reasons that I have given above, I think it should be 'harm' understood in the way that I have described and not simply 'suffering' when it comes to the intending harm requirement. This is because otherwise we would have to conclude (to use some of the above examples) that whipping the masochist who enjoys it cannot count as punishment, and neither can the imprisonment of a committed stoic (as long as that does not affect her virtuousness). This is because presumably neither of them has any negative emotions towards their respective treatments and therefore are not suffering as a result of those treatments. The masochist thoroughly enjoys the whipping, while the committed stoic, firmly believing that nothing can harm her as long as she remains virtuous, is not bothered by the imprisonment at all and therefore has no feelings towards it. If punishment requires that they

\footnotetext{
${ }^{25}$ Leo Zaibert, Punishment and Retribution (Aldershot: Ashgate 2006), 49-58. A list of all the conditions that he thinks is necessary for punishment can be found in ibid 31-33.

${ }^{26}$ Wringe (n 2) 26.

${ }^{27}$ Hanna also spoke in terms of 'suffering' in his earlier work (e.g. n 13 and n 24 - he claims to be using the term as 'a sort of catchall' on p 329 of the latter). In contrast, he uses 'harm' more specifically in his more recent paper "The Nature of Punishment: Reply to Wringe," Ethical Theory and Moral Practice 20 (5) (2017): 969-976.

${ }^{28}$ It is true, as Hanna observes (ibid fn 3), that Wringe does not just speak in terms of 'suffering' but also 'harm' and 'burdensome treatments'. However, I think it is clear from the text that he is primarily thinking in terms of 'suffering' when talking about the kind of intention that is required for punishment.
} 
This is a post-peer-review, pre-copyedit version of an article published in Law and Philosophy. The final authenticated version is available online at: http://dx.doi.org/10.1007/s10982-019-09353-7.

suffer as opposed to being harmed in the more general sense that I have described, then neither of them can be said to be punished in those two cases.

Very little attention has been given to whether the intention that is required for punishment is 'harm' more generally or 'suffering' more specifically. Rich has recently offered an argument in favour of the latter and against the former. According to Rich, what is intended in punishment must be 'suffering' more specifically because "... if [it is] not to make the offender feel the sting of her criminal conviction, it is very hard to see why hard treatment would be imposed at all" (Rich makes clear she is talking about motivation rather than justification here)..$^{29}$

I fail to see why the only motivation for punishment is to "make the offender feel the sting of her criminal conviction" or (to put it in a non-legal context) make the wrongdoer feel the sting of the judgement that she has committed a wrong. It seems possible that one can also be motivated to punish an offender simply because one believes she deserves, in virtue of her wrongdoing, to have her life made worse off and therefore 'harmed' in this more general sense independent from how she so happen to experience it. I admit this might not be a good justification for punishing an offender, but it seems to me a perfectly possible and intelligible motivation for it. For this reason, I remain unconvinced by Rich's argument that we should reject the intending harm requirement and instead adopt an 'intending suffering requirement' ${ }^{30}$

It is important to distinguish the intending harm requirement from the more specific intending suffering requirement. This is because Wringe's dissent seems to be at least partly

\footnotetext{
29 Sylvia Rich, "Corporate Criminals and Punishment Theory," Canadian Journal of Law and Jurisprudence 29 (1) (2016): 97-118, 110-111.

${ }^{30}$ Rich offered the argument to show corporations cannot be punished since while they can be harmed more generally, they are unable to experience suffering. In rejecting her argument here, I do not find it particularly problematic to accept the implication that corporations can also be punished.
} 
This is a post-peer-review, pre-copyedit version of an article published in Law and Philosophy. The final authenticated version is available online at: http://dx.doi.org/10.1007/s10982-019-09353-7.

motivated by the potential implications of the latter and not the former. Thus before he goes on to show how his alternative view of hard treatment can still adequately distinguish punishment from other non-punitive kinds of hard treatments, Wringe says the following:

"If I inflict on you some treatment which is designed to cause you to suffer, and you do not in fact suffer, then I have to that extent failed... But if I intend to inflict on you some treatment which would typically cause suffering in individuals like you and you do not suffer, then I have not necessarily failed... Perhaps I have failed because, very unusually, you have become a convinced Stoic while awaiting sentence, and now believe that imprisonment is not a way in which you can be harmed. Or perhaps you have fallen into an uncharacteristic state of insensibility. In these cases, I have not necessarily failed in the goal of inflicting treatment that someone like you would normally find burdensome". ${ }^{31}$

This passage suggests that Wringe is eager to allow for the possibility of successful punishment even in cases when it fails to cause suffering on those who are punished - the firm and sincere stoic and the grieving parent who, for example, is so traumatised by the loss of her own children (perhaps as a result of her own wrongdoing) that she feels nothing towards anything that might befall on her now. However, as I have argued earlier on, what these cases show is that we should instead reject the narrower intending suffering requirement in favour of the broader intending harm requirement. This is because it is

\footnotetext{
${ }^{31}$ Wringe (n 2) 26-27.
} 
This is a post-peer-review, pre-copyedit version of an article published in Law and Philosophy. The final authenticated version is available online at: http://dx.doi.org/10.1007/s10982-019-09353-7.

possible to harm the stoic and the grieving parent even when they do not suffer as a result of the harmful treatment.

Furthermore, as Hanna points out, it is not clear whether Wringe's alternative to the intending harm requirement can rule out cases that we intuitively might not count as punishment. ${ }^{32}$ To recall, Wringe argues that the hard treatment in punishment should simply be a "treatment that would normally be found burdensome by a typical individual of the kind on whom it is being imposed". ${ }^{33}$ However, we can imagine someone who does not want nor intend to harm an offender, but in order to quell public anger, decided to reprimand the offender in response to her wrongdoing by imposing on her something that would normally be found burdensome by a typical individual of her kind, all the while knowing that she is in fact rather atypical and will not find it burdensome at all. Hanna's intuition, which I also share, is that this is arguably not a case of punishment, but pretend punishment at the very most. If that is true, then this suggests that Wringe's alternative is inadequate and what is needed is the intending harm requirement instead. ${ }^{34}$

Zaibert's argument, on the other hand, applies to both the intending suffering requirement and the intending harm requirement since it targets more specifically the 'intention' part of the requirements. Zaibert thinks that we should include in punishment not just the harms that were intended but also those that were known. In support of this, he asks us to imagine a parent who punishes her son by having him grounded in his bedroom in response to his wrongdoing. However, the parent also knows that her son's bedroom is

\footnotetext{
${ }^{32}$ Hanna (n 27) 970-971.

${ }^{33}$ Wringe (n 2) 26.

${ }^{34}$ This example is based on the one offered by Hanna but modified to take into account the other conditions that Wringe thinks are essential to punishment. Like me, Wringe also accepts the response requirement that I shall discuss in the next section, but unlike me he is open to the possibility that the expressive function is indeed essential to punishment.
} 
This is a post-peer-review, pre-copyedit version of an article published in Law and Philosophy. The final authenticated version is available online at: http://dx.doi.org/10.1007/s10982-019-09353-7.

infested with poisonous snakes even though she does not wish nor intend her son to be bitten by them. If her son is indeed bitten by them, Zaibert claims, this harm should be seen as part of the punishment that is inflicted on the child by his parent. Indeed, Zaibert goes on to modify this example further, and argues that even the harms that were simply foreseen by the parent and hence recklessly imposed on the child should also count as part of the punishment in question. $^{35}$

It is unclear why one should follow Zaibert here, unless one already shares his intuition about the two cases. What seems to be motivating Zaibert here are worries about the further harms that can foreseeably (often with virtual certainty) be inflicted on prison inmates as a result of a badly managed and underfunded prison system. ${ }^{36}$ I share his worry, but excluding such foreseeable harms from being part of the punishment in question does not make them immune from criticism or any less objectionable. Even if the snake bites do not form part of the punishment, we can still criticise the above parent for punishing her child by sending him to his bedroom despite knowing that her child will be harmed much more seriously than she intends and is warranted as punishment. Similarly, it is wrong to punish people by sending them to badly managed and underfunded prisons when we know this will expose them to all sorts of personal violence that arguably goes beyond the kind of harm that incarceration is meant to impose and is warranted as punishment; and this remains the case whether we consider the personal violence as part of the punishment or not. Given that I do not share Zaibert's intuition about his two cases nor see the motivation behind his position, I therefore remain unpersuaded.

\footnotetext{
35 Zaibert (n 25) 49 \& 52.

${ }^{36}$ Ibid 57.
} 
This is a post-peer-review, pre-copyedit version of an article published in Law and Philosophy. The final authenticated version is available online at: http://dx.doi.org/10.1007/s10982-019-09353-7.

Before I move on to the next section, let me address two possible counterexamples to the intending harm requirement as I have defended it. The first one is (a) where a judge, faced with a homeless offender in a bitter winter, sentences her to imprisonment so that she won't freeze to death. The second one is (b) where a judge, who does not want nor intend to harm an offender, but in order to quell public anger, sentence a thief to precisely the community service that she knows the thief (for some reason) enjoys doing and was planning to do anyway. One might think these are cases of successful punishment despite that the offender is not harmed in both cases. ${ }^{37}$

It is important to note what is required for punishment is simply that an offender is harmed in one respect or another, not that her life is made worse off on the whole or all things considered. ${ }^{38}$ Since being locked up and deprived of one's freedom and liberties does, I tend to think, makes one's life worse off in one respect even when it makes one's life better off all things considered, (a) is therefore not a case of 'harmless punishment' that can pose a problem for the intending harm requirement. ${ }^{39}$

I agree that the offender is not even harmed in this minimal sense in (b); but I also tend to agree with Hanna here that the offender is not really punished in such a case. ${ }^{40}$ Here I want to distinguish between being punished and simply being subjected to something that the law recognizes as punishment, and maintain that (b) is a case of the latter but not the former. However, similar to what I have discussed earlier, none of this implies that the offender in question should (or should not) be subjected to further punishments. It all

\footnotetext{
${ }^{37}$ My thanks to a reviewer for highlighting the need to address these two potential counterexamples.

${ }^{38}$ See also n. 18

${ }^{39}$ These two cases also highlight the difficulties with the intending harm requirement for institutional cases of punishment, since those who impose punishment on behalf of the institution (e.g. the judges in our criminal justice system) can frequently not have the required intention. I shall say more about this at the end of the next section.

${ }^{40}$ Hanna (n 27) 971.
} 
This is a post-peer-review, pre-copyedit version of an article published in Law and Philosophy. The final authenticated version is available online at: http://dx.doi.org/10.1007/s10982-019-09353-7.

depends on the justificatory theory of punishment that is under consideration, i.e. whether it is justifiable to subject the offender to other punishments that would actually harm her despite her already being subjected to what the law recognizes as punishment. As far as this paper is concerned, I remain open on this particular normative issue.

Furthermore, even if the offender is not really punished in (b), it does not imply that she cannot have a right to appeal because there is nothing about which she may appeal against. This relates to the 'response requirement' that I shall discuss in the next section. Insofar as an offender is subjected to something that the law recognizes as punishment, then even if the sentence itself - the community service - does not actually harm the offender, it is nevertheless something that is ostensibly imposed on her in response to her being found guilty for committing a wrong. ${ }^{41}$ Thus even if the offender is actually not harmed by the sentence in question, she may still appeal against the fact that she was found guilty and being ostensibly sentenced in response to that finding. Thus, accepting that the offender is not really punished in (b) does not imply the counterintuitive conclusion that the offender therefore has no right to appeal simply because she was not harmed by the sentence in question. ${ }^{42}$

\section{Hard Treatment Imposed in Response to Alleged Wrongdoing}

So far I have been focusing on the element of hard treatment in the standard account of the nature and definition of punishment; and I have argued that this involves intentionally

\footnotetext{
${ }^{41}$ I say 'ostensibly' here and I take that to be sufficient for the immediate purpose. However, as I shall discuss at the end of the next section, in institutional cases of punishment such as (b), there are reasons to think that sometimes the response requirement can indeed be satisfied (and not just ostensibly so) even when the judge who works on behalf of the institution does not take her wrongdoing as a reason for imposing the sentence in question. See txt at n 54 through to $\mathrm{n} 59$.

${ }^{42}$ My thanks to a reviewer for raising this objection.
} 
This is a post-peer-review, pre-copyedit version of an article published in Law and Philosophy. The final authenticated version is available online at: http://dx.doi.org/10.1007/s10982-019-09353-7.

harming the person who is being punished. Equally important is that this hard treatment is intentionally imposed on an alleged offender in response to her alleged wrongdoing. This is because punishment is not mere gratuitous injury or wanton violence. Rather, there is a reason (or at least an alleged reason) for the intentional infliction of harms; it is intentionally imposed on an individual because she has (or is at least believed to have) committed a wrong. Or in other words, what distinguishes punishment from other kinds of intentional infliction of harms is that committing a wrong is taken to be a reason for intentionally harming the individual in question. I shall refer to this as the "response requirement". ${ }^{43}$

It is important to note that the response requirement does not amount to an implicit endorsement of a retributive justificatory theory of punishment. This is because the response requirement merely states that committing a wrong is simply taken as a reason for intentionally harming the individual question. This is consistent with it actually not being a sufficient reason or even a reason for intentionally harming the individual in question.

One implication of the response requirement is that one cannot be punishing another when one sincerely believes that the other has not committed any wrong. This is because one cannot be regarded as acting in response to $\mathrm{X}$, or take $\mathrm{X}$ as a reason for action, when one sincerely believes that $X$ is false (' $X$ ' here being that the individual in question has committed a wrong). The response requirement therefore excludes from punishment what Rawls refers to as "telishment", in which one treats another as having done wrong and 'punishes' her for it even when one knows that she is has not done any wrong but because doing so will, for example, lead to certain good consequences. ${ }^{44}$ The response requirement, however, does not

\footnotetext{
${ }^{43}$ Boonin (n 2) 17-18. Boonin calls this the "retributive requirement". I have changed his terminology here because of its possible mistaken association with retributive justificatory theories of punishment, as I shall explain in the next paragraph.

44 John Rawls, "Two Concepts of Rules," The Philosophical Review 64 (1955), 3-32, 11.
} 
This is a post-peer-review, pre-copyedit version of an article published in Law and Philosophy. The final authenticated version is available online at: http://dx.doi.org/10.1007/s10982-019-09353-7.

exclude accidental punishments, in which we end up punishing an innocent person despite our best efforts to establish the case at hand. It also does not exclude those who we end up punishing because they were (unknown to us) framed by others, neither does it exclude those who we punish because we were insufficiently attentive when establishing whether she has committed a wrong. ${ }^{45}$ However, because the response requirement does rule out telishment as a kind of punishment, one might object to it as constituting a 'definitional stop' ${ }^{46}$

I don't think there is anything per se objectionable to define 'punishment' in such a way that excludes telishment, any more than it is to define 'square' in such a way that excludes anything with less or more than four sides. What is objectionable, however, is how such a definition is sometimes used in debates about the justification of punishment.

Thus Hart talks about how some consequentialists, when confronted with the objection that their justificatory theory would allow the punishment of those who are sincerely believed to have not committed any wrongs if it leads to better consequences, would simply respond that this is not true since they are merely 'telished' and not 'punished'. Hart's response to this is to include telishment as a sub-standard or non-central case of punishment. ${ }^{47}$ For my part, I would insist that the normative burden is not discharged simply because one is 'telished' as opposed to being 'punished'. ${ }^{48}$ It remains to be shown why it is justifiable to telish someone simply when it would be beneficial to do so, i.e. to treat someone who one knows has not done any wrong as if she has and 'punish' her for it just because this would lead to certain good consequences.

\footnotetext{
${ }^{45}$ For a more detailed discussion of these different forms of 'punishing the innocent', see Patrick Tomlin, "Innocence Lost: A Problem for Punishment as Duty," Law and Philosophy 36 (2017): 225-254, 229-230. I have separated out the case of being insufficient attentive from his case of being indifferent. This is because I fail to see how one is acting in response to $X$ when one is utterly indifferent towards whether $X$ is true or not. His case of being indifferent is therefore another kind of telishment.

${ }^{46}$ Hart (n 5) 5-6.

47 Ibid.

${ }^{48}$ See also Zaibert (n 25) 27-28.
} 
This is a post-peer-review, pre-copyedit version of an article published in Law and Philosophy. The final authenticated version is available online at: http://dx.doi.org/10.1007/s10982-019-09353-7.

Instead of defending them, one can also use the 'definitional stop' to criticise the consequentialists. The thought here is that since such theories seek to justify punishment in light of the future consequences that it promotes, what it ends up justifying is not a practice of punishment that takes wrongdoing as a reason for harming the alleged wrongdoer (i.e. the response requirement), but a totally different practice that takes the promotion of future consequences as a reason for harming the alleged wrongdoer - or indeed anyone as it is in the case of telishment. ${ }^{49}$ One might then object to the response requirement as being unfair to the consequentialists, as it excludes their justificatory theory of punishment by definitional fiat. ${ }^{50}$

The mistake here is to think that the response requirement excludes consequentialist justificatory theories of punishment when it in fact does not. Rather, it only determines what exactly needs to be justified here. Thus what consequentialist justificatory theories of punishment need to show is that consequentialist considerations can be sufficient to justify taking the supposed fact that someone has committed a wrong as a reason for harming her, and therefore intentionally harming her as a response to her alleged wrongdoing. If consequentialist justificatory theories succeed in doing this, then so much the better for them; but if they fail to do so, then so much the worse for them. Of course, it is possible that consequentialist considerations can also end up justifying things that go beyond or are different from punishment, for example telishment and even intentionally harming someone with no pretence of wrongdoing on her part simply in order to avert a future disaster. However, the question here is not about all these other examples of non-punishment but

\footnotetext{
${ }^{49}$ This seems to be the version of 'definitional stop' argument that John Gardner pressed against Hart in his Introduction to the 2 nd edn, of Punishment and Responsibility (n 5) xxv-xxvi.

50 See also Boonin (n 2) 20-21. Note that Boonin does not characterize it as a kind of 'definitional stop' argument.
} 
This is a post-peer-review, pre-copyedit version of an article published in Law and Philosophy. The final authenticated version is available online at: http://dx.doi.org/10.1007/s10982-019-09353-7.

whether consequentialists can successfully justify punishment in the way I have described. Of course, such examples can and do call into question the (consequentialist) justificatory strategy that underlies consequentialist justificatory theories of punishment, but they do so whether they count as punishment or not. Thus, although I agree that the response requirement does constitute a 'definitional stop' - i.e. that any intentional harms that are not imposed in response to alleged wrongdoing in the sense I have described are simply by definition not punishments - there is nothing objectionable about it. It neither confers an unfair advantage nor an unfair disadvantage to consequentialist justificatory theories of punishment.

Nevertheless, there is an ambiguity with the response requirement as it currently stands. An ambiguity that might lead one to conclude that even if we accept the response requirement, we are still unable to distinguish punishment from other kinds of intentional infliction of harms. Boonin, for example, describes a case in which a prospective gang member (call her 'prospect') goes through a rite of initiation by being branded with a hot iron, but only on the condition that she commits a wrong, like stealing a car. In such a case, it seems that the prospect is intentionally harmed precisely because of and in response to the fact that she committed the wrong in question. Yet, this clearly is not a case of punishment. Boonin takes this to support the inclusion of a censorial/reprobative function in the definition and nature of punishment. ${ }^{51}$

I believe Boonin is too quick in accepting the alleged inadequacy of the response requirement here. It is true that, perhaps from an impartial and objective point of view, the prospect has committed a wrong - she has done something that she ought not to have done.

\footnotetext{
51 Ibid. 22-23.
} 
This is a post-peer-review, pre-copyedit version of an article published in Law and Philosophy. The final authenticated version is available online at: http://dx.doi.org/10.1007/s10982-019-09353-7.

In that sense she is therefore intentionally harmed precisely because and in response to her wrongdoing. However, there is another sense in which that is not true; for we can imagine that in cases of such kind neither the prospect nor the gang itself and its members really see and accept what the prospect has done as something that she really ought not to have done. ${ }^{52}$ They might very well use the terminology of 'wrong' and 'ought' when describing what she has done; but they do not see it as something that she has decisive and/or good reasons to not do. Rather, they see it as something that she has good reasons to do, or indeed decisive reasons to do especially if she wants to join the gang. From this point of view, it is not true that the prospect is intentionally harmed because of and in response to her wrongdoing; for she has not done something that is seen or accepted as something she ought not to have done.

Rather than showing the inadequacy of the response requirement, Boonin's example shows that there is a need to disambiguate the response requirement. What matters to the nature and definition of punishment is not whether, from an impartial and objective point of view, those who are intentionally harmed have done something that they ought not to have done. Rather, it is whether they have done so in the sense that I have described above, i.e. that it is seen or accepted as something they really ought (in that full sense of 'ought') not to have done..$^{53}$ It is only when someone is intentionally harmed in response to this is the response requirement fulfilled and that the case at hand is an instance of punishment.

\footnotetext{
52 I shall address cases where this presumption does not hold later in this section.

${ }^{53}$ Another way to understand what I mean here is in terms of what H.L. A. Hart refers to as the "internal points of view" and the "internal aspect of rules"; that is, to have a "critical reflective attitude" towards the behaviour(s) prescribed by the norm in question (which the wrongdoer has now violated), see it as a standard for conduct and this is manifested in "criticism (including self-criticism), demands for conformity and in acknowledgements that such criticism and demands are justified..." (The Concept of Law $2^{\text {nd }}$ edn. (New York: OUP, 1994), 57 \& 89).
} 
This is a post-peer-review, pre-copyedit version of an article published in Law and Philosophy. The final authenticated version is available online at: http://dx.doi.org/10.1007/s10982-019-09353-7.

It is of course possible to stipulate this clarification into an example, though it is much harder to imagine that in relation to the kind of initiation ceremonies discussed above. This is because we are asked to imagine a case where stealing, for example, is both genuinely seen and accepted as something that one ought not to do; but also as something that one should nevertheless be rewarded for doing, and be granted with the privilege to join the ranks of the organizations in question. A more plausible, and I believe more intelligible, example is one where a group of wrongdoers have come together in light of their wrongdoings - say to do some good - and have decided to mark themselves out as a group by branding each other with a hot iron. However, unlike Boonin's example, it is now less clear that this is indeed not a case of punishment, and that the intentional harms in such cases are not simply (selfinflicted) punishments.

So far I have talked in terms of 'seeing or accepting' $\mathrm{X}$ as a wrong, and 'taking $\mathrm{X}$ as a reason for' imposing the harm in question. This suggests that what matters when it comes to whether or not something is an instance of punishment are the mental states of those who are inflicting the harm and/or those who are directing it. As long as they see or accept that what someone has done is wrong in the sense described above, and take that as a reason for imposing the harm in question, then they are punishing her. Thus in my above response to Boonin's example, I have simply assumed that everyone who is involved - and in particular those who are doing the branding and those who are directing it - all share the gangs' view in that what the prospect has done is not a wrong. However, imagine instead that the person who is directing it or the person who is inflicting it does not share the gangs' values. Unbeknownst to others, she does see what the prospect has done is something that she indeed ought not to be have done, and take that as a reason for branding the prospect. In that case it does seem that the prospect is being punished by the person in question, albeit 
This is a post-peer-review, pre-copyedit version of an article published in Law and Philosophy. The final authenticated version is available online at: http://dx.doi.org/10.1007/s10982-019-09353-7.

privately since it is unbeknownst to others. One can imagine the outrage that the gang members and the prospect would feel had this come to light, and how she would be labelled (quite rightly I think) as an 'opportunistic punisher'.

However, it is not only in virtue of peoples' mental states that we may say a conduct is seen or accepted as a wrong and is taken as a reason for the imposed harm. Very often we speak of institutions as seeing or accepting that it is wrong to engage in certain kinds of conducts and taking that as a reason for imposing the harms in question. ${ }^{54}$ Insofar as that holds in the particular case at hand, then what we have is an instance of punishment even when those who are working on behalf of the institution does not so happen to have the requisite mental states. ${ }^{55}$ Thus we can imagine a judge who regularly sentences offenders on behalf of our criminal justice system but does so without the requisite mental states. This might be because she only sees it as a job, or because she does not share the institution's view that the kinds of conducts in question are indeed wrongs but continued on in order to keep her job. While we might have questions about the moral integrity of the judge here, I contend that in both cases what she is imposing on behalf of the criminal justice system are still punishments, as long as the institution in which the judge is working on behalf of does indeed see or accept the kinds of conducts in question as wrongs and take that as a reason for harming those who engage in them.

Admittedly, both the intending harm requirement and the response requirement are more straightforward in cases of non-institutional punishments than they are in cases of

\footnotetext{
${ }^{54}$ I shall say more about the latter later on; but one reason for thinking that the former holds is when those who work on behalf of the institution has what Hart refers to as the "internal point of view" and therefore a "critical reflective attitude" towards the behaviour in question. This in turn is manifested through the language that they use to describe the behaviour and their readiness to demand others not to engage in the said behaviour and criticise those who do. See also n. 53.

55 None of this means that wrongdoers are therefore punished twice if those who work on behalf of the institution in such cases also so happen to have the requisite mental state. The two perspectives are merely two different ways in which we can characterize what is being imposed as an instance of punishment.
} 
This is a post-peer-review, pre-copyedit version of an article published in Law and Philosophy. The final authenticated version is available online at: http://dx.doi.org/10.1007/s10982-019-09353-7.

institutional punishments. The latter involves attributing intention and agency to a group of actors in a way that is not simply reducible to the intentions and agencies of its individual actors. This raises all sorts of thorny questions about the metaphysical status of such collective intentions and agency, what is the grounding for them and how they relate to those of individual actors even when they are not simply reducible to them. Answering these questions, however, require a separate discussion and a paper in its own right. ${ }^{56}$

What I instead want to point out for the purposes of this paper is that despite all these thorny metaphysical questions, there are nevertheless other reasons for thinking when an institutional practice satisfies the intending harm requirement and the response requirement. Thus one reason for thinking that an imposition is intended to harm someone is that this is the aim or purpose of the imposition in question and that the imposition is normally considered to be unsuccessful if that person is not harmed by it. ${ }^{57}$ Insofar as we have reasons to think that this is the case for the kinds of harms that are imposed by the institution in question, then leaving aside thorny questions about group agency and intention, there are also reasons to think that what we have here are intended harms and is therefore something that satisfies the intending harm requirement for punishment. ${ }^{58}$

\footnotetext{
${ }^{56}$ But see e.g. Christian List \& Philip Pettit, Group Agency: The Possibility, Design and Status of Corporate Agents (Oxford; New York: OUP 2011); Margaret Gilbert, A Theory of Political Obligation: Membership, Commitment and the Bonds of Society (Oxford; New York: OUP 2006), esp. Part II; and Peter French, Collective and Corporate Responsibility (New York: Columbia University Press 1984). For a more particular discussion of this in relation to legal punishment, see Wringe $(\mathrm{n} 2) \mathrm{ch} 3$.

${ }^{57}$ Note that this does not imply that people will always be punished again whenever their original punishment was unsuccessful. As mentioned earlier (txt at $n$ 40), there might be reasons against imposing another punishment even when the original one was unsuccessful. Thus one might not be punished again simply for these reasons.

${ }^{58}$ Admittedly the name 'intending harm requirement' is not the most ideal as it might give undue emphasis on the existence of a certain identifiable mental state as being necessary for punishment. Rather, what is necessary for punishment is simply that it is aimed at harming the wrongdoer. Thus in one of his latest articles Hanna refers to the same requirement as the 'Aim to Harm Requirement' instead (n 27). In this paper I have simply followed Boonin ( $n$ 14) and refer to the requirement with its arguably more conventionally recognized name.
} 
This is a post-peer-review, pre-copyedit version of an article published in Law and Philosophy. The final authenticated version is available online at: http://dx.doi.org/10.1007/s10982-019-09353-7.

The same can also be said for the response requirement. One reason for thinking that $\mathrm{X}$ is a response to wrongdoing is that it is normally considered to be a mistake to have $\mathrm{X}$-ed, if it turns out that there was no wrongdoing in the sense that I have described. ${ }^{59}$ Insofar as there are reasons to think this holds in the institutional cases in question, then just like the above with the intended harm requirement, there are also reasons to think that the response requirement is also satisfied in those institutional cases.

It is also important to distinguish between punishment and telishment in institutional cases. ${ }^{60} \mathrm{~A}$ case of the latter would be one in which the institution in question does not (for one reason or another) actually see or accept $X$ as a wrong - hence it cannot be a case of punishment as the response requirement cannot be satisfied - but it nevertheless (for other reasons) treats it as a wrong, and those who have X-ed as having committed a wrong and ostensibly 'punish' them by subjecting them to hard treatment for committing it. Examples of such cases of telishment, I think, can be found in criminal offences that are deliberately overinclusive, e.g. statutory rape and assisted suicide. It seems plausible to suggest that at least in some of these cases the state does not actually see or accept those who commit such offences as necessarily committing a wrong, for example when there is genuine consent in the former and when the latter is well-motivated and done in response to a genuine request. Nevertheless, it still criminalises all such conducts and prohibits anyone regardless from having sex with an underage person and assisting others in their attempts at suicide, provides no defence for those who are brought to trial and are found to have committed either of them, and basically treat them as if they have indeed committed a wrong and ostensibly 'punish' them by subjecting them to hard treatment for committing the two offences.

\footnotetext{
${ }^{59}$ Wringe (n 2) 31-32.

${ }^{60}$ See txt at n 44 through to $n 50$.
} 
This is a post-peer-review, pre-copyedit version of an article published in Law and Philosophy. The final authenticated version is available online at: http://dx.doi.org/10.1007/s10982-019-09353-7.

Whether or not it is justifiable for the state to do all this and telish people, however, is a separate and open question. As I have pointed out in my earlier discussion, the mere fact that one is telished as opposed to being punished does not make it any more justifiable. The same also applies to institutional cases of telishment.

Before I move on to the next section, let me also discuss another possible example against the standard account in relation to the response requirement. It seems self-defence poses a difficulty here. This is because self-defence typically involves intentionally harming someone that is also often done in response to her wrongdoing. This then suggests that the expressive function of punishment is needed in addition to the standard account after all. ${ }^{61}$

I disagree. There is a distinction between responding to a past or pre-existing wrong and responding to a future anticipated wrong, and what punishment involves is the former while what self-defence involves is the latter. ${ }^{62}$ What this shows is that there is possibly another ambiguity with the response requirement, and that the response requirement should be understood more precisely as only referring to 'responding to past or pre-existing wrongs'. Understood in such a way, the standard account can then distinguish punishment from selfdefence without resorting to the expressive function of punishment.

Note that this does not mean people cannot be punished for attempting to commit a wrong. This is because what the punishment is responding to in such cases is not the future

\footnotetext{
${ }^{61}$ See e.g. ibid 33.

62 See also Boonin (n 2) 193. More specifically, self-defence involves responding to a future anticipated wrong/harm that could have occurred had one not intervened and defended oneself. Thus someone who is confident in her ability to defend herself is still responding to a future anticipated wrong/harm in that sense when she defends herself. As one reviewer points out, this way of understanding self-defence implies that it is not an instance of self-defence when one defends oneself from an attack even when one believes (rightly or wrongly) that the attack will be unsuccessful. This is because in such a case one could not be responding to a future anticipated wrong/harm. I think this is correct. It is a further question, however, whether in such a case one is nevertheless entitled to harm the attacker in order to repel the attack because one's belief can be mistaken and that the attack will actually be successful. I remain open on this further question. My thanks to a reviewer for raising these further issues relating to my understanding of self-defence.
} 
This is a post-peer-review, pre-copyedit version of an article published in Law and Philosophy. The final authenticated version is available online at: http://dx.doi.org/10.1007/s10982-019-09353-7.

wrong that the offender is currently attempting to commit, but the current wrong of attempting to commit a wrong. What the response requirement does exclude, however, are 'pre-punishments' from being a kind of punishment. These are cases where someone is supposedly 'punished' for wrongs that they have yet to commit. ${ }^{63}$ Finally, it is also worth mentioning that nothing I have said so far about the difference between self-defence and punishment implies that any attempt which seeks to justify punishment based on self-defence is necessarily doomed. ${ }^{64}$ This is because what is at stake with such justificatory theories of punishment is not whether punishment is simply a kind of self-defence and is therefore justifiable in the same way. Rather, it is whether the same or similar kind of considerations that render self-defence justifiable can also render it justifiable to punish, i.e. to intentionally harm someone in response to a past or pre-existing wrong that she has committed.

\section{Feinberg's Mere Penalties and Other Examples}

Once it is properly spelled out and understood, the standard account can indeed adequately account for the kind of examples that Boonin alleges it cannot. What about Feinberg's mere "penalties", which includes "parking tickets, offside penalties, sackings, flunkings, and disqualifications"? As I have pointed out earlier, it is not clear why all instances of the above are not and should not be considered as punishments. Flunkings are not typically considered to be punishments; neither should they be so considered, for they are not normally harms that are intended and imposed as responses to wrongdoing in the sense that

\footnotetext{
${ }^{63}$ For a vivid illustration of such a regime, see e.g. the 2002 Hollywood film Minority Report. What we have here is therefore also another 'definitional stop'. See txt at n. 46 for a discussion of the worries that one might have about such 'definitional stops'.

${ }^{64}$ Examples of such attempts include e.g. Warren Quinn, "The Right to Threaten and the Right to Punish," Philosophy and Public Affairs 14 (1985): 327-373 and more recently Victor Tadros, The Ends of Harm (New York: OUP 2011).
} 
This is a post-peer-review, pre-copyedit version of an article published in Law and Philosophy. The final authenticated version is available online at: http://dx.doi.org/10.1007/s10982-019-09353-7.

I have discussed. Rather, they normally are only foreseeable harms that are imposed in responses to failures in assessments that have nothing to do with wrongdoing (e.g. exams in schools). Being disqualified to drive, on the other hand, can be a punishment for driving dangerously; but one can also be disqualified to drive by failing (i.e. flunking) a license renewal test (if there is one), and that is not nor should it be considered as a punishment. The same can also be said for sackings. One can be sacked for committing a wrong at one's work place, but one can also be sacked for failing to live up to the boss's expectations. What distinguishes those disqualifications and sackings that are punishments and those that are not is precisely the standard account: if the harms that are imposed are intended and imposed as responses to wrongdoing in the sense that I have argued for, then they are and should indeed be considered as punishments; otherwise, they are not and should not be considered as punishments.

What about parking tickets and offside penalties? Contra Feinberg, I do think that they are punishments, for they are typically intended harms that are imposed in response to what are at least seen or accepted as something that the relevant individuals ought not to have done. It is just that while the former is a legal punishment for a legal offence, the latter is a non-legal punishment for breaking the rules of a game. There is no reason to think that just because offside penalties are non-legal punishments for a non-legal offence, it is therefore not a kind of punishment.

One thought that is quite common among criminal lawyers and theorists, which I take is related to Feinberg's mere "penalties" but is nevertheless distinct from it, is that we should distinguish between 'real' crimes that are subject to (criminal) punishments and 'quasi- 
This is a post-peer-review, pre-copyedit version of an article published in Law and Philosophy. The final authenticated version is available online at: http://dx.doi.org/10.1007/s10982-019-09353-7.

crimes' that are subject to penalties. ${ }^{65}$ The latter of which typically includes parking tickets for parking offences. One way to maintain this distinction is precisely by appealing to the expressive function of punishment: penalties for 'quasi-crimes' are distinguished from punishments for 'real' crimes because the hard treatments in the former, unlike those in the latter, do not convey a censorial/reprobative message about what the alleged offender has allegedly done. Should this distinction be abandoned in light of what I have argued for?

I do not think so. It all depends on how exactly we are to understand this distinction. Although I argue against the expressive function of punishment, I nevertheless accept that the hard treatment in punishment (or particular instances of it) can also sometimes be used or so happen to be seen as conveying censure/reprobation for wrongdoings. Given that the hard treatment in punishment is (as I have argued) intended to harm those who are punished and is imposed in response to their alleged wrongdoing, and that censure/reprobation is also something that is considered to be supposedly painful and hurtful that is done in response to alleged wronging, it is not surprising that the hard treatment in punishment is also sometimes seen and/or used as a vehicle for conveying censure/reprobation. What I want to deny is simply that it being so seen or so used is either a necessary, an essential or a defining feature of punishment.

Accordingly, a distinction between 'criminal punishments' and 'penalties' can still be maintained by how the hard treatment in the former, unlike that in the latter, so happens to be seen or is used to convey a censorial/reprobative message. It is just that this difference should now not be taken to imply that the 'penalties' for 'quasi-crimes' are therefore not punishments. To the extent that both 'criminal punishments' and 'penalties' fulfil the

\footnotetext{
${ }^{65}$ While such a distinction is not formally drawn in English law, comparable kinds of distinctions are drawn in German law between Straflaten and Ordnungswidrigkeiten, and in the Model Penal Code between offences as crimes and offences as violations (MPC s. 1.04). See also Duff, "How not to Define Punishment" (n 2) 40.
} 
This is a post-peer-review, pre-copyedit version of an article published in Law and Philosophy. The final authenticated version is available online at: http://dx.doi.org/10.1007/s10982-019-09353-7.

conditions set out in the standard account that I have argued for above, then both of them should be considered as punishments; it is just that the hard treatments in the former are also used or so happen to also be seen as conveying a censorial/reprobative message. ${ }^{66}$ Whether there are good reasons to continue on using or seeing them in such a way is, however, a separate question.

\section{Conclusion}

I have tried to argue against the expressive function of punishment in this paper by undermining the arguments that have been offered in support of it. In particular, I have argued that this expressive function is not needed to properly distinguish punishments from other kinds of non-punitive hard treatments. Rather, the standard account by itself can already do the job adequately, once the intending harm requirement and the response requirement in the standard account are properly clarified and understood. Thus contrary to the arguments that have so far been offered for the expressive function of punishment, the need to distinguish punishment from other kinds of non-punitive hard treatment is not a good reason for accepting it. Unless there are other forthcoming arguments (to which I am inclined to think there are none), then it seems there are no good reasons to accept the expressive function of punishment in addition to the standard account of the nature and definition of punishment.

I have also discussed how denying the expressive function of punishment is consistent with the fact that the hard treatments in punishment (or particular instances of them) can sometimes be used or so happen to be seen as conveying a censorial/reprobative message.

\footnotetext{
${ }^{66}$ To the extent that is true, it might be useful to distinguish between 'criminal punishments' and 'penalties', though not in terms that somehow imply that one is punishment and the other is not.
} 
This is a post-peer-review, pre-copyedit version of an article published in Law and Philosophy. The final authenticated version is available online at: http://dx.doi.org/10.1007/s10982-019-09353-7.

This is not surprising since, as I have explained earlier, censure/reprobation and punitive hard treatments are both things that are done in response to alleged wrongdoings and are supposedly harmful and/or painful to those who are subject to them (indeed intended to be so in the latter cases). I believe this helps to explain why one might be inclined to accept the expressive function of punishment. However, doing so would be to mistake contingent features of punishment with features that are necessary, essential or definitive of it. 